Please do not remove this page

RMIT

UNIVERSITY

Revenue, access, and engagement via the in-house curated Spotify playlist in Australia

Morgan, Benjamin

https://researchrepository.rmit.edu.au/esploro/outputs/9921861178501341/filesAndLinks?institution=61RMIT_INST\&index=null

Morgan, B. (2020). Revenue, access, and engagement via the in-house curated Spotify playlist in Australia. Popular Communication, 18(1), 32-47. https://doi.org/10.1080/15405702.2019.1649678

Document Version: Accepted Manuscript

Published Version: https://doi.org/10.1080/15405702.2019.1649678

Repository homepage: https://researchrepository.rmit.edu.au

(C) 2019 Taylor \& Francis Group, LLC.

Downloaded On 2023/04/26 21:55:08 +1000

Please do not remove this page 
Accepted for publication in Popular Communication, permanent link http://dx.doi.org/10.1080/15405702.2019.1649678

202018 (1) pp. 32-47

Benjamin A Morgan

RMIT University

Digital Ethnography Research Centre

\section{Revenue, access, and engagement via the in-house curated Spotify playlist in}

\section{Australia}

ABSTRACT: This article analyzes the perception of recording industry change in Australia through a focus on the curated playlist as a new sociotechnical intermediary. During the rapid expansion of commercial music streaming services between 2016 and 2018, musician and recording industry enthusiasm for revenue growth was tempered by trepidation surrounding change. This article presents findings from interview research conducted with Australian artists and music industry professionals to provide insight on the promotion of popular music within the digital music streaming commodity. It explores the apprehension and enthusiasm over the affordances of the new recommendation and discovery ecosystems through the discourse around the in-house curated Spotify playlist. Analysis will demonstrate the increasingly influential role music streaming platforms are perceived to play in the sectors of retail, promotion, and distribution.

Keywords: Australia, digital media, information society, media industries, new media, popular music, sound studies, work and labor 


\section{Introduction}

Between 2016 and 2018, popular press coverage of music streaming services kept up the tradition of sensationalist rhetoric that has surrounded the emergence of new technologies which effect popular music. Reporting frequently relied on narratives portraying music streaming as a savior resurrecting the recording industry from the dead (Ellis-Petersen, 2016; Nicolaou, 2017). These coexisted with skeptical reports claiming that streaming was unfair to artists, or "how the music industry is putting itself out of business" (Gerber, 2017). As scholars of media and/or technology should expect, the discussion around streaming services within the industry was far more nuanced and specific than the blunt moralistic frames presented in the popular press. Those meta-narratives and moral frames around streaming are simplistic distractions from more useful questions regarding what new practices, concerns, and norms emerge when the affordances of new technologies affect the popular music commodity.

Acknowledging that the recording industry of the 20 th and early 21 st centuries has so far been a superstar model where a handful of sustainable successes fund failures (Marshall, 2013) and that "the majority product of the music industry is not success but failure" (Jones, 2003, p. 148), my research is based on the belief that there are "more and less equitable ways to divide the industry's wealth, and to develop methods to insure its continuing growth and innovation" (Sinnreich, 2016, p. 154). Conducted as the qualitative element of Australian Research Council linkage project Music usage metrics and the future of the Australian music industry, it examines the role of streaming technology in changing practices through interviews with Australian industry stakeholders and artists. 
Given that there are both empowering and exploitative narratives around the affordances and structures of streaming to be explored, this study of how stakeholders view change in the Australian music industries ${ }^{1}$ contributes to critical media industries research, which "needs to be underpinned by an engagement with social theory, with empirical work (which means an engagement with methodological problems and dilemmas), and with a politics opposed to inequality and injustice" (Hesmondhalgh, 2009, p. 253). This qualitative project on the production and distribution of popular music in Australia is intended to inform existing and future systems for the generation of revenue from popular music with evidence reflecting the needs and concerns of the Australian recording industry as streaming was surpassing other formats as the primary revenue source for recordings.

Music streaming services were seen to be impacting industrial practice and strategy in a variety of ways, but the scope of this article is to explore stakeholder views in the Australian recording sector around the Spotify in-house curated playlist, in order to help make sense of related debates regarding revenue, access, and engagement. It will examine the discourse around changing practice within both the realms of commercial marketing and promotion strategy (distribution). As a micro study on media production and distribution, it seeks a better understanding of the "intertwining of economics and culture in capitalism" while acknowledging that there are contradictory elements of both emancipation and domination to be found in debates around media industry production under capitalism (Hesmondhalgh,

\footnotetext{
${ }^{1}$ The music industries encompass the broad monetization of music, including the recording industry, live performance, and other revenue streams. This preference for the plural reflects older definitional work (Sterne, 2014; Williamson \& Cloonan, 2007) and in particular Nordgård (2018) who also views the streaming services as external actors to the music industries.
} 
2009, p. 253). While labor practice and commercial strategy are often the discussion topics, this research is ultimately concerned with the meanings and standards constructed through practice.

\section{Interview sample and Australian context}

My research follows the attitudes of artists and professionals in the Australian music industries around technology in semi-structured interviews. The interview sample $(n=30)$ consists of emerging and aspiring popular musical performers $(n=7)^{2}$ and professional stakeholders involved in the monetization of artist brands across multiple industry sector roles: large independent record labels $(n=2)$, small independent record labels $(n=2)$, artist managers $(n=5)$, publishers $(n=4)$, aggregators/distributors $(n=2)$, live concerts $(n=2)$, marketing services $(n=2)$, a retailer $(n=1)$, a technology services consultant $(n=1)$, royalties accountant $(\mathrm{n}=1)$, and a radio producer $(\mathrm{n}=1)$.

The Australian popular music sector has been described as a "small marketplace, heavily reliant on cultural imports" where it "can be a difficult place to succeed and to create ongoing careers," due largely to a low population density and large distances between major cities (Strong \& Rogers, 2016). Despite its geographic isolation and perceived fondness for importing popular music, it is also positioned by industry as a strong exporter hoping to be the source of "five per cent market share of the global music market by 2030" (Australia, 2019, p. iv), while domestic consumption of recordings was ranked as the eighth largest

\footnotetext{
${ }^{2}$ Self-reported artist genres (acts typically cited 2-3 genres): Indie (5), Pop (3), Rock (2), Electronic (2), Funk (1), Hip Hop (1), Alternative (1), Roots (1), Soul (1).
} 
market in the world overall in 2018 (IFPI, 2019, p. 13).

The risk-reducing economic structures of stardom, which can be found wherever the global recording industry is well-established, encourages overproduction and is a model where very few artist brands are able to become sustainable successes (Marshall, 2013; Negus, 1999). However, there is an Australian angle to mediating this prevalence of failure. Based on research conducted with musicians in Brisbane, (Rogers, 2013) argues that the production of popular music in Australia is centered around amateurs and hobbyists, with professionalization into a sustainable career often seen as secondary to the immediate pleasures of producing. This suggestion that success is not primarily defined as a sustainable career by many Australian musicians is also supported by (Hughes, Keith, Morrow, Evans, \& Crowdy, 2013), which found that intermediate success and satisfaction in achievement were more appropriate descriptors for success in Australia than traditional metrics of financial independence or peer respect/recognition. All artists that were interviewed for this study relied on income derived outside of music production, all seven had hired staff to work on campaigns and had released records. Four employed managers, and five employed booking agents at the time of interviews. While this sample lacks the voice of any stars deriving their entire livelihood from popular music production, it is reflective of the status of the vast majority of Australian artists in the process of pursuing careers as producers of popular music.

The Australian music industries are supported through policies designed to protect and support the production of local content. Funded grants to support different stages of production and promotion for artist brands are offered through Federal organizations such as the Australia Council for the Arts and Sounds Australia, state bodies like Creative Victoria, Create NSW, and QMusic, as well as local and industry initiatives. One particular notable institution is the publicly-funded national youth broadcaster Triple $\mathrm{J}$, "a unique blend of 
public service and niche marketing" (Albury, 1999, p. 55) widely regarded as the most important and influential gatekeeper for the youth music market. While policy to support local content within the streaming format was under discussion, interviews focused on how new technology affected everyday practice and strategy for promoting the artist brand within the existing promotional infrastructure of intermediaries and technological tools. Noting concerns raised by several scholars about applying research with creative workers in highly developed markets to the rest of the world (Alacovska \& Gill, 2019; De Beukelaer, 2015; Morgan, 2019), the findings of this paper should be linked to Australian cultural market conditions.

I spoke with a broad range of sector professionals, and several participants held multiple roles. One interview ought not be interpreted as representative of an entire sub-sector role. All industry participants were either sole proprietors or held management positions at firms. Staff at multi-national major record labels/publishers and commercial streaming companies declined to participate in this research. It is important to note that audiences also play a central role in shaping practice, but this study is concerned with how industry stakeholders and artists contribute to the formation of standards and meaning around popular music. While several other studies have looked at how users engage specifically with streaming platform playlists (Hagen, 2015) or algorithmic recommendation systems (Karakayali, Kostem, \& Galip, 2017) in consumption practice, this article examines the perspective of producers and professionals around promotion and distribution.

The interview methods and theoretical grounding are based on other scholarly studies on how music industries have reacted to digitalization and new tools (Baym, 2011, 2018; Hesmondhalgh \& Meier, 2018; L. M. Meier, 2017; Nordgård, 2018; Wikström, 2013). The conceptual approach of Keith Negus (1999), who interviewed and observed music producers and professionals in order to analyze how their culture produces the industry, guides this 
investigation.

\section{Locating the in-house curated Spotify playlist: a new form of sociotechnical cultural intermediary}

The intended object of interrogation, the in-house curated Spotify playlist is a specific entity within the digital music commodity known as a streaming service, a relatively new format ecosystem for consuming popular music. Streaming services offer various methods of algorithmic recommendation, search, and customization intended to keep the user within their ecosystem by continually suggesting more songs to listen to. The branded virtual space itself is the commodity on offer, and the commodity is defined no longer merely by the music being listened to, but by infrastructures which are intentionally designed to trap the user and keep them listening as long as possible by continually suggesting new songs (Seaver, 2018). This combination of distribution and discovery roles of the digital music streaming commodity has created new tensions arising from the expectation of these services to constantly provide promotion of songs in order to prolong consumption (Kjus, 2016).

The revenue-generating streaming services which monetize streams and pay copyright owners through licensing agreements were frequently referred to by participants as DSPS (for digital service providers), but also as online stores, subscription services, streaming sites, and platforms. ${ }^{3}$ During this period in Australia, DSPs referred to Spotify, Apple Music, Google

${ }^{3}$ Platform is a term commonly applied to these companies, and Spotify itself is noted to describe itself as a music streaming subscription service or an audio platform depending on context. but the usage of the term platform in academia carries theoretical implications that cannot be addressed here, and will be avoided. 
Play, Amazon, and Tidal. DSP appears to be a relatively new music industry term. ${ }^{4}$ Stakeholders at larger music companies were fond of using it, but it was still unfamiliar to several participants. DSPs grant access to large catalogs owned by record labels, offer playlists and recommendations to promote recordings, and monetized the streams.

The recommendation features within these branded virtual spaces are new forms of cultural intermediaries. Originally used by Pierre Bourdieu to refer to "producers of cultural programmes on TV and radio or the critics of 'quality' newspapers and magazines and all the writer-journalists and journalist-writers" (Bourdieu, 1984, p. 325), this is a theoretical model for studying people (or in this case, an opaque hybrid of people and algorithms) who function as gatekeepers which acknowledges that they are involved in the shaping of popular taste. Bourdieu's concepts of non-economic capital are useful when discussing playlist pitching to make sense of the professional networks (social capital) and experience, education, and knowledge within the field (cultural capital) that are involved with gatekeeping and access (Bourdieu, 1986).

This concept has been useful for understanding the role of record labels, publicists, concert promoters, and many other cultural industry workers in adding value and contributing to the success or failure of popular songs and artist brands over the years (L. Meier, 2013; Negus, 1999, 2002). Powers (2015) conceptualization of intermediation moves this conception away from individuals towards a "dynamic process of circulation that involves people, symbolic forms, and objects as much as it involves the modes of transportation and transmission that allow these elements to be linked" (p.122). Morris (2015) builds on this by conceiving of DSPs as digital infomediaries which mine, monitor, and mediate their audiences, while

4 Vonderau (2017) reports the usage of DSP referring to Demand-Side Platforms, but that usage is focused on a particular segment of the advertising supply chain within Spotify's platform ecosystem. 
noting that it is now particularly important to understand how algorithms are reconfiguring the work of cultural intermediaries. Webster, Gibbins, Halford, and Hracs (2016) combine Bourdieu's concept of cultural intermediaries with Actor-Network Theory's insistence on the relational ontology of human and nonhuman actors, arguing that the music recommender systems within the DSPs should be approached as a new form of "sociotechnical cultural intermediary" (p.141). This term is particularly appropriate given the combination of human and algorithmic curation involved in the management of Spotify's in-house playlists.

While Spotify is functioning as an infomediary at the institutional level, it was their recommendation ecosystem which had become the main topic of interest for artist managers, labels, and publishers interested in promoting releases by their artist brands. This recommendation ecosystem included featuring artist brands or recordings on the interface, algorithmic auto-generated tailored song suggestions based on past activity, and a large number of playlists. These different methods of recommendation are all gatekeeping mechanisms which allow certain recordings to be highlighted, suggested, or even automatically played in lieu of others. While all users and third-party institutions could create their own playlists and allow others to access them, it was the playlists which Spotify created and managed in-house which were perceived by participants to be the key to the largest potential audience. As I also learned, the degree to which algorithmic vs. human curation played a role in managing these playlists was not well-understood by participants. ${ }^{5}$

\footnotetext{
${ }^{5}$ (Prey, 2016) provides a breakdown of how Spotify's algorithmic recommendation engine the Echo Nest generates personalized recommendations. (Eriksson, Fleischer, Johansson, Snickars, \& Vonderau, 2019) lays out the broad functionality of the entire Spotify system, but neither of these sources shed more light into how in-house playlists are specifically managed beyond how Spotify reports that they are: managed by human curators and informed by metrics.
} 


\section{Curated playlist: the instrument of new affordances}

The curated playlist is a mechanism whereby DSPs are able to combine format affordances in promotion, distribution, and retail of recordings which can aid in the discovery ${ }^{6}$ of new songs, deliver them, and facilitate payment. These playlists are often based on genre, though Spotify's specialties include mood- and activity-based playlists that promise the ideal soundtrack to match an activity or a desired feeling, such as Boozy Brunch, Songs to Sing in the Car, Putting Baby to Sleep, or Deep Focus. While some of the playlists are focused on the concept of a musical theme (e.g. I Love My '00s R\&B, JazzRap), the popularity of soundtracking-your-life playlists does indicate a shift towards a more contextual application of music based on the listener's location, activity, and state of mind. These particular playlists are examples of what some participants refer to as lean back music - a more passive approach to song selection that is often based on context.

While the exact procedures of how Spotify playlists are curated is opaque, journalists have profiled some of the human curators and their methods (Ugwu, 2016). Interview data confirms that Spotify, Apple Music, and Google Play employed human curators who accepted pitches to support new releases for playlists (and other online editorial features within the sites). These in-house curated playlists are different than user-generated personal playlists and those created by outside firms which are also known as third-party playlists. There is a market for promoting songs to the third-party playlisters, which do not enjoy the

\footnotetext{
${ }^{6}$ Discovery is also an important term to problematize, the subject of a special issue in this journal in 2016. See (Nowak, 2016) on the differentiated approaches to discovery as a phenomenological act. Discovery here is understood as the mechanism where listeners are exposed to new recordings through recommendation, and (Kjus, 2016) notes: 'The degree to which these services manage to convince artists, labels and consumers of the virtues of discovery may well be decisive for the future of the streaming model.' (p. 129).
} 
same placement and focus within the site. While some labels had looked into third-party playlisting promotion, none had hired them. Unless otherwise noted, curated in-house playlists are the type of playlist under discussion.

Playlists are the embodiment of the new affordances of DSPs - the ability to promote the discovery of a particular song, enable the delivery, charge the listener, and compensate the copyright owner(s). This consolidates formerly distributed power with one entity, which bypasses existing intermediaries. It also reduces cost and system friction and presents an alternate promotional pathway through which to promote recordings to radio broadcasting, the traditional gatekeeper of popular success. While the emergence of a new option to promote through was Three particularly volatile areas of debate about playlists can be seen in the topics of revenue, access, and engagement.

\section{Revenue on playlists: enthusiasm and pessimism}

Reported streaming revenues accounted for $38 \%$ of the Australian recorded music market in 2016 , growing to $54 \%$ in 2017 , and climbing to $71 \%$ of a sector worth $\$ 526$ million AUD in 2018, (ARIA, 2019; Australia, 2019, p. 6).The controversy surrounding artist royalties for streams was a high-profile debate well-covered in the popular media and analyzed by scholars (Marshall, 2015; Sinnreich, 2016). I anticipated that revenue rates would be a major topic. My first surprise finding was that artists and industry stakeholders were not interested in talking about streaming rates. Global and local journalists were continuing to report on criticism about transparency and fairness in streaming rates first raised by popular artists such as David Byrne (Byrne, 2015), Taylor Swift (Swift, 2015), or Thom Yorke (Dredge, 2013) and enforced by research white papers (Fair Music: Transparency and payment flows in the music industry, 2015; Lalonde, 2014). A major finding of this research is that participants 
were not (or were no longer) focused on rates of payment or transparency of payment by streaming sites as issues of concern.

A few performers were pessimistic about ever earning an income from streaming, e.g. "artists don't make any money from streaming, especially local artists" (Amy Wilson, personal communication, 2017). These skeptical statements came from the artists with lower stream numbers. Enthusiasm about the growth of streaming revenue was strong with large labels, publishers, managers, and perhaps most surprisingly, from the manager of an unsigned artist who had experienced playlist and subsequent national radio support in 2016-17 without signing to a record label: Melbourne artist LANKS, who was an artist without a record deal at the time I spoke with his manager, Lou Cuming.

The opportunity that Spotify especially has given us with playlisting has meant that our income's grown from nothing to tens of thousands of dollars per year. So, purely from a discovery and a financial point of view, Spotify kind of represents the most lucrative and the most beneficial of the streaming services for what we're doing. (Lou Cuming, personal communication, 2017)

Cuming's comments were the most enthusiastic that I encountered around streaming revenue in the interviews. The support LANKS was enjoying was indicative of a successful emerging act, which is important to differentiate from other aspiring unsigned acts who were not receiving the same level of playlist support. Of the seven artists interviewed, three had performed on songs which had stream counts in the millions on Spotify. None of those artists with higher stream counts verbalized the sentiment that the payments they were receiving were unfair.

Some artists with lower stream counts and the smaller record label stakeholders gave statements that streaming was not yet a significant revenue stream for them, stating that the 
purchase of a physical copy or merchandise was still the proper way to ensure financial support for a young artist. In contrast, the larger labels, publishers, and managers were all enthusiastic about the ability of DSPs to generate revenue, which industry reports would subsequently confirm were growing in Australia at very impressive rates. Reported streaming revenues accounted for $38 \%$ of the Australian recorded music market in 2016, growing to $54 \%$ in 2017 , and climbing to $71 \%$ of a sector worth $\$ 526$ million AUD in 2018, (ARIA, 2019; Australia, 2019, p. 6).

The narratives around streaming royalties for independent artists as a revenue source as unfair or have been noted by Marshall (2015). The example of LANKS finding success and revenue without a record label via the playlist demonstrates that emancipatory claims of streaming enabling creators to bypass powerful intermediaries such as record labels can cite certain cases as evidence. Overall, this interview sample was not critical of payment rates for streams, an unsigned artist's manager was very positive about the revenue, industry professionals were enthusiastic about the ability of playlists to generate revenue, and everyone viewed playlists as important promotional tools, even when they were skeptical about the revenue ever becoming significant for them.

\section{Access to promotion through playlists: clear pitching and opaque placement}

"Spotify's mixes are replacing radio as the most powerful promotional tool in music" wrote Lucas Shaw in Bloomberg Businessweek (2018), and this perception of a powerful role of playlists in promotion and discovery was supported by interview data. Artist manager Monica's support of this narrative was typical of how participants viewed playlisting in 2017- 
18:

Spotify is so huge for music discovery now, because that's how people are finding out about new music instead of listening to radio. Spotify has become this place with all the generated playlists, and they just keep feeding out playlists to the masses. That's how people are discovering their new music. (Monica, personal communication, 2017)

Monica's perception of how Spotify playlisting was becoming the dominant form of music discovery was supported by other participants, regardless of whether they personally listened to them. The new perceived supremacy of playlists to promote songs was noted and echoed by the global press (Forde, 2017). This perceived transition from playlists as tools for users to organize their consumption to a powerful tastemaking vehicle can be summarized by Carl Chery, then an Apple Music playlist curator who has since moved to Spotify: 'I'm getting to a point where I'm so far ahead of things that I'm actually able to shift them. Instead of reacting to what's happening, I have a hand in shaping what's happening" (Ugwu, 2016).

The narrative of playlists becoming the new radio, or the most important method with which to promote songs, is indicative of the perception that playlists have become intermediaries, able to influence and affect popular taste and consumption. While interview data confirms that human curators handled the initial decision to add new tracks to playlists, the exact role of humans vs. automated algorithmic systems in the movement of tracks within the playlist ecosystem is opaque. Participants who pitch playlist curators are unsure and uninformed about how decisions to move or drop recordings within the ecosystem are subsequently made. A story in WIRED magazine reported that Spotify's metric evaluations of a performance of a song will largely determine what happens once it is in the ecosystem (Pierce, 2017). Both human and algorithmic forces are reportedly at play when deciding what 
happens to tracks in the playlist ecosystem, and this was confirmed by Sarah Hamilton, operations manager for aggregator Ditto Music.

"The editors for the different genres at Spotify will often put a song on New Music Friday to test it and see how people react to it, and then move it on from there...I think they're seeing how people respond to music by looking at data and analytics." (Sarah Hamilton, personal communication, 2017)

Hamilton's role at Ditto music was just one example of a new position that has emerged in the wake of the platformization of the recording industry: aggregators were offering independent artists the kind of promotional services which were traditionally handled by record labels. While Ditto Music allowed anyone to use their distribution service to deliver music to multiple DSPs, the bespoke playlist pitching service was reserved for artists which Ditto selects. This was also the case with MGM Distribution.

Because we're dealing with independent artists, some of them don't have labels. Some of them don't even have management. I personally take on the role of pitching them to the different services. (Beth Deady, personal communication, 2017)

While "gut feeling" and the perceived ability of a song to "connect" are cited as the reasons particular songs are added (Hamilton, 2017), the cultural and social capital of stakeholders like Hamilton and Deady also play a role in their ability to get songs onto playlists. They act as gatekeepers within their own clientele, then pitch their selections to the gatekeepers at the streaming services. In interviews, it was made clear that human ears selected which songs get added, though metric evaluation of the song's performance - skip rate, shares, saves, and other responses by the user - all affected placement of the track in an opaque manner. This dynamic re-evaluation is exemplary of Powers' concept of intermediation as a process. 
It was the cultural and social capital that professionals like Hamilton and Deady have generated through their work in the digital music sector which allowed them to hold positions to assist songs which they selected to enter the playlist ecosystem. Afterwards, allegedly metrics and algorithms take over and performance replaces intermediary capital as grounds for action. Soliciting playlists was not a very different procedure than how pitching radio, press, or any other gatekeeper tends to work: personal relationships are developed over time, earning certain stakeholders better access to curators through repeatedly proving an ability to be effective at selecting recordings which perform well. Managers, labels, distributors/aggregators, and publishers informed me that they could pitch songs to Spotify's curators during this time by emailing a form, but publicists reportedly were not welcome.

Accusations of playola - paying to have songs added to a playlist - circulated in this period, as documented in trade magazine Billboard. However, the report did not specify clearly whether in-house curated or third-party playlists were the topic, and the playlist promotion companies described in the article were third-party companies owned by the major record labels (Peoples, 2015). Despite this ambiguity, subsequent news articles about Spotify's playlists emphasized the narrative of curation decisions being largely metric and performance-based (Pierce, 2017; Ugwu, 2016). Journalist Liz Pelly reported that major labels controlled most of the editorial content and playlist slots, while also reporting on the ability for rights owners to pay to have sponsored songs appear on playlists (Pelly, 2017). All participants denied hiring playlist promotion companies or paying for playlist placement.

Despite journalistic reports of possible manipulation and a dominance of the major label artists within the playlist ecosystem, the lack of clarity on how Spotify was actually making their decisions was troubling and confusing participants more than what the major labels or playlist promotion companies were up to. Several artists speculated that even "an algorithm is also going to favor major labels' artists, or whatever, because of certain money going into it, 
right?" (Dan, personal communication, 2017).

While Apple Music uses more human curation as point of difference in their brand (Morris \& Powers, 2015), the more algorithmic quality of the highly-influential Spotify playlists was on everyone's mind, even if they did not understand how it worked. As Brian, the director of a publishing company with several decades of experience noted:

The access to those playlists is becoming the new radio, or television...But now, the playlists are clearly the way the game is, and that is open to manipulation. Now, I'm not saying that Spotify is manipulating, but the way these lists are being created is not entirely clear. (Brian, Publisher, interview, 2017)

While Brian was well aware that playlist pitching involved human curators, it is the opaque sociotechnical nature of how the ecosystem was subsequently managed that was concerning to him. The nuances of how the opaque algorithmic structures on Spotify functioned were not well-understood, and the platform did not share information about why decisions regarding song placement were made.

Nearly all participants were aware that gaining access to the playlists involved a pitching procedure, though the less experienced artists were unsure who they would need to engage to help them with this. Ronnie Frew from rock band Pink Harvest demonstrates the perception of a young artist without an experienced manager or label informing them as to specifics. After describing how their band receives mass mailed emails from companies promising to help them with playlist placement or boosting metric numbers, Frew notes that any kind of help requires hiring people, or spending money.

My general opinion is that there's a money stream, no matter what. You might do it the moral way, or the way the industry considers moral. You're still probably paying 
something to do it. You might pay a publicist a certain amount of money that probably will get the same amount of views and they are technical views of actual people, but there's always money that starts it. It starts the process, unless you spend a lot more time (Ronnie Frew, personal communication, 2017).

Frew's words represent those of someone who knows that access will require capital and the support of other human intermediaries to gain access to the sociotechnical playlist environment, though the specifics are unclear. While experienced playlist pitchers like Deady and Hamilton and industry veterans like Brian are aware of how to leverage their cultural and social capital to help songs gain access, the specifics of how the playlists are managed are opaque.

Playlist pitching became less mysterious in July, 2018, when Spotify announced that all playlist pitches would subsequently need to originate from the artist or label's account (Spotify, 2018b). Playlist pitching was thereby reframed as no longer an exclusive and mysterious domain for industry insiders. While nothing prevents pitching experts from continuing to solicit curators via the Spotify interface, the change is one of several announcements by Spotify in 2018 which appear on the surface intended to disintermediate existing intermediaries. Overall, these announcements indicated a goal to create more direct relationships between artists and Spotify. ${ }^{7}$ However, existing relationships between curators and pitchers would not necessarily be affected by this change in pitching procedure.

The lack of clarity and information regarding how playlists were being managed was

\footnotetext{
${ }^{7}$ The announcement of the new pitching process was followed in September, 2018, by the announcement that artists could upload music directly into the Spotify system without using an aggregator (Spotify, 2018a)
} 
frustrating to industry professionals, in particular those managers, label staff, and publishing professionals who had more experience with having their songs on playlists. Possibly unfair access to lists through power and/or money were in comparison only a slight concern mentioned by artists. While several artists, managers, and small labels expressed tension around focusing too much on Spotify's metric and data-driven tools, not a single respondent denied the perceived power of playlists to generate streams. The emerging key role of playlists as influential sociotechnical gatekeepers was not questioned. Access to playlists was still seen as reliant on humans pitching to other humans, while the role of algorithms in managing playlists was opaque and mysterious.

\section{Playlists and engagement: Who was that artist?}

The role of playlists as a focal point for discovery of new tracks evolved out of audiences embracing the format. Mary Beth Ray's study of digital music consumption in the USA predates the focus on curated playlists as promotional tools, but shows that playlists emerged as crucial for everyday listening through enabling the avoidance of the labor of active curation, as well as managing the overwhelming choice offered by the vast amount of music available (Ray, 2017). The rise in streaming revenue during this period appears directly linked to the rise of playlist usage in the minds of many, and a quantitative study by the European Commission supports this: “Getting on Today's Top Hits is worth almost 20 million additional streams, which translates to $\$ 116,000$ and $\$ 163,000$ in additional revenue from Spotify alone" (Aguiar \& Waldfogel, 2018).

While a strong perception of playlists' value for promoting a release to generate streams and revenue was consistent within the sample, concerns about the playlist as possibly detrimental 
to the long-term engagement of the listener with artists was on the mind of several participants on the industry side, such as Chris Maund of large independent label Mushroom Group.

One issue with streaming, is that playlists are akin to radio. To use an overused expression, it's lean back, not lean in, and it means that a lot of people are being fed the music rather than going out and discovering it. It's having a huge impact. I think albums are a great artistic outlet, and clearly streaming is affecting that. The emphasis from a financial/release/promotion point of view is moving away from albums. While I get that is the new order, it's a shame, culturally. (Chris Maund, personal communication, 2017)

While the unbundling of the album in favor of focusing on individual tracks is a relatively old story in the narratives of digital disruption, it is the additional lack of active searching for the song that Maund refers to here that is the new cause for concern. Listening to a personal collection involves interaction with an archive and active selection of which albums or tracks to play. Listening to radio is, comparatively, perceived as completely passive and noninteractive. Streaming playlists are perceived to encourage similar passive listening within an interactive setting where the listener still has control of selection. While radio and plenty of other forms of music placement (e.g. synchronization, public performance of recordings) are established passive conduits for getting songs into the ears of the public, playlists are in this case framed as an encroachment of passive listening into the previously interactive realm of personal use.

There are two highly relevant differences to listening via playlist streaming to a personal collection or to the radio: 1) with all playlists, but in particular mood- and context-based ones, the aural experience of hearing the music is often not the primary focus. Rather, the 
listening becomes a soundtrack, or even a functional element designed to attune the listener to the activity. This is particularly notable in the numerous playlists that are framed to be listened to while working out or studying, and 2) unlike radio, there is no voice notifying the listener of what they are listening to. The listener is required to stop what they are doing and engage the Spotify interface in order to determine any information about the track.

This concern about the relative lack of artist/fan engagement on the playlist was especially on the minds of more experienced stakeholders, those at the larger labels and publishing companies. Concerns whether this lack of engagement could mean that playlist streams are not a good metric for measuring actual artist support were vocalized by Phil, another participant with decades of experience in the Australian music industries.

A lot of streams are driven by passive playlist listening, something which can provide an income for an artist to help sustain and grow their career. However, that doesn't mean that you're in any way building an engaged fanbase or will be breaking through in a bigger way. An artist needs to dive deeper and look beyond the numbers to understand the context and where the streams are coming from to provide a better view of engagement with their fans. (Phil, personal communication, 2017)

Managers, label, and publishing professionals also noted that because of this concern about streams being an unreliable metric of engagement, an artist's follower count was seen as a stronger indicator than streams. This observation about how to interpret data seemed to be a recent insight, and best practices around how to handle the different metrics and usage data seemed to be changing quickly, especially once Spotify launched their "Spotify for Artists" portal in April 2017 (Spotify, 2017).

Stories regarding artists who had high stream counts being unable to draw the expected audience were mentioned by participants from labels and live concert firms, and a few of 
these stories were shared with me at conferences. By 2018, journalists and industry analysts began picking up on these concerns about playlisting, as well as the reliance on streams as an indicator of genuine fandom. "Streaming analytics stripped of the context of insight can mislead. Lean-back hits are not real hits," according to industry analyst Mark Mulligan (Mulligan, 2018), and journalist Cherie Hu wrote in November 2018 that we are entering a "post-playlist reality" marked by decreased confidence in the ability of playlists as vehicles for discovering music, developing artist careers, and/or improving the overall music industry. (Hu, 2018). While the interview sample was more focused on determining how to get access to playlists, the seeds of doubt in the vitality of curated playlists as always good for artist development can be found in the remarks of the industry veterans. This ambiguity and fallibility of streaming metrics to properly measure engagement echoes the findings of Nancy Baym about the unreliability of social media metrics for measuring genuine engagement (Baym, 2013).

\section{Conclusion}

The curated in-house playlist is the mechanism whereby DSPs such as Spotify are able to combine their affordances in promotion, distribution and retail to create an instrument for generating streams for particular songs which consolidates power and creates new sociotechnical intermediaries. This creates revenue, though the discovery of new songs through playlists is perceived to be lacking in artist/fan engagement. Journalists and trade publications have noted the popularity of streaming and subsequent growth in revenue, questioned the fairness of their revenue rates, probed the ability of money to influence curation of playlists, and were beginning to question their limitations as tools for artist development.

The interview sample shows a general enthusiasm over growing revenue from streaming from 
industry stakeholders, while the artists and small labels who do not see significant revenue from streaming are skeptical that it will be as significant as physical sales as a revenue stream for them. The absence of strong rhetoric claiming that streaming is inherently anti-artist and devaluing recordings was notable during this period. Lack of clarity on how Spotify was managing their playlists was more of a concern than issues of access or unfair influence, and participants who were familiar with the pitching process confirmed that human curators granted access, while the role of metrics and algorithms in managing the playlists was opaque.

The power of Spotify playlists to generate streaming numbers and revenue was never questioned by participants.

We can see how the affordances of DSPs to shape listening choices as well as generate revenue combined to make playlisting the major new promotional concern of this era. Concerns regarding engagement and the long-term effects of the popularity of the playlist format on artist development were on the minds of several veterans. These interviews document a period in Australia where DSPs have taken the lead in revenue generation and are consolidating power in promotion. There was enthusiasm to be found for new intermediaries, but concerns and confusion about the increased reliance on opaque algorithmic automation. The lack of artist/fan engagement via the playlist was the emerging concern. 


\section{Cited Research Interviews}

Brian pseudonym (2017). Director, large music publishing company

Cuming, Lou (2017). Artist manager, Mister Management

Dan pseudonym (2017). Songwriter and performer

Deady, Beth (2017). Digital Asset Manager, MGM Distribution

Frew, Ronnie (2017). Songwriter and performer, Pink Harvest

Hamilton, Sarah (2017). Operations manager, Ditto Music

Monica pseudonym (2017). Artist manager

Maund, Chris (2017). Chief Operating Officer, Mushroom Group

Phil pseudonym (2017). Managing director, large music publishing company

Wilson, Amy (2017). Songwriter and performer, Mere Women

\section{Works Cited}

Aguiar, L., \& Waldfogel, J. (2018). Platforms, Promotion, and Product Discovery: Evidence from Spotify Playlists. Retrieved from https://ec.europa.eu/jrc/sites/jrcsh/files/jrc112023.pdf

Alacovska, A., \& Gill, R. (2019). De-westernizing creative labour studies: The informality of creative work from an ex-centric perspective. International Journal of Cultural Studies, O(0), 1367877918821231. Retrieved from https://journals.sagepub.com/doi/abs/10.1177/1367877918821231. doi:10.1177/1367877918821231

Albury, K. (1999). Spaceship triple J: Making the national youth network. Media International Australia incorporating Culture and Policy, 91(1), 55-66.

ARIA. (2019). ARIA 2018 Music Industry Figures Show 12.26\% Growth [Press release]. Retrieved from 


\section{SPOTIFY PLAYLIST AUSTRALIA}

https://www.ariacharts.com.au/news/2019/aria-2018-music-industry-figures-show-12-26-growth

Australia, P. o. (2019). Report on the inquiry into the Australian music industry. Canberra Retrieved from https://www.aph.gov.au/Parliamentary Business/Committees/House/Communications/Australianmu $\underline{\text { sicindustry/Report }}$

Baym, N. K. (2011). The Swedish model: Balancing markets and gifts in the music industry. Popular Communication, 9(1), 22-38.

Baym, N. K. (2013). Data not seen: The uses and shortcomings of social media metrics. First Monday, 18(10). Retrieved from http://firstmonday.org/ojs/index.php/fm/article/view/4873/3752. doi:10.5210/fm.v18i10.4873

Baym, N. K. (2018). Playing to the Crowd: Musicians, Audiences, and the Intimate Work of Connection. New York: New York University Press.

Bourdieu, P. (1984). Distinction a social critique of the judgement of taste. London: Routledge \& Kegan Paul. Bourdieu, P. (1986). The forms of capital (R. Nice, Trans.). In J. Richardson (Ed.), Handbook of Theory and Research for the Sociology of Education (pp. 46-58). New York: Greenwood.

Byrne, D. (2015). Open the Music Industry's Black Box. The New York Times. Retrieved from http://www.nytimes.com/2015/08/02/opinion/sunday/open-the-music-industrys-black-box.html

De Beukelaer, C. (2015). Developing Cultural Industries: Learning from the Palimpsest of Practice. Amsterdam: European Cultural Foundation.

Dredge, S. (2013). Thom Yorke calls Spotify 'the last desperate fart of a dying corpse'. Retrieved from http://www.theguardian.com/technology/2013/oct/07/spotify-thom-yorke-dying-corpse

Ellis-Petersen, H. (2016). Music streaming hailed as industry's saviour as labels enjoy profit surge. The Guardian. Retrieved from http://www.theguardian.com/technology/2016/dec/29/music-streamingindustry-saviour-labels-spotify-apple-music

Eriksson, M., Fleischer, R., Johansson, A., Snickars, P., \& Vonderau, P. (2019). Spotify Teardown: Inside the Black Box of Streaming Music: Mit Press.

Fair Music: Transparency and payment flows in the music industry. (2015). Retrieved from https://www.berklee.edu/sites/default/files/Fair\%20Music\%20\%20Transparency\%20and\%20Payment\%20Flows\%20in\%20the\%20Music\%20Industry.pdf

Forde, E. (2017). 'They could destroy the album': how Spotify's playlists have changed music for ever. 


\section{SPOTIFY PLAYLIST AUSTRALIA}

Retrieved from https://www.theguardian.com/music/2017/aug/17/they-could-destroy-the-albumhow-spotify-playlists-have-changed-music-for-ever

Gerber, R. (2017). How The Music Industry Is Putting Itself Out Of Business. Forbes. Retrieved from http://www.forbes.com/sites/greatspeculations/2017/05/03/how-the-music-industry-is-puttingitself-out-of-business/

Hagen, A. N. (2015). The Playlist Experience: Personal Playlists in Music Streaming Services. Popular Music and Society, 38(5), 625-645. Retrieved from http://dx.doi.org/10.1080/03007766.2015.1021174. doi:10.1080/03007766.2015.1021174

Hesmondhalgh, D. (2009). Politics, theory and method in media industries research. In J. Holt \& A. Perren (Eds.), Media Industries History, Theory, and Method (pp. 245-255). Malden/Oxford: Wiley-Blackwell. Hesmondhalgh, D., \& Meier, L. M. (2018). What the digitalisation of music tells us about capitalism, culture and the power of the information technology sector. Information, Communication \& Society, 21(11), 1555-1570. Retrieved from https://doi.org/10.1080/1369118X.2017.1340498.

doi:10.1080/1369118X.2017.1340498

Hu, C. (2018). Our new "post-playlist" reality. Retrieved from https://www.getrevue.co/profile/cheriehu42/issues/our-new-post-playlist-reality-138493

Hughes, D., Keith, S., Morrow, G., Evans, M., \& Crowdy, D. (2013). What constitutes artist success in the Australian music industries? International Journal of Music Business Research (IJMBR), 2(2), 61-80.

IFPI. (2019). Global Music Report 2019: State of the Industry. Retrieved from https://www.ifpi.org/downloads/GMR2019.pdf

Jones, M. (2003). The Music Industry as Workplace: An approach to analysis. In A. Beck (Ed.), Cultural Work: Understanding the Cultural Industries (pp. 147-156). London: Routledge.

Karakayali, N., Kostem, B., \& Galip, I. (2017). Recommendation Systems as Technologies of the Self:

Algorithmic Control and the Formation of Music Taste. Theory, Culture \& Society, 0263276417722391. Retrieved from http://dx.doi.org/10.1177/0263276417722391. doi:10.1177/0263276417722391

Kjus, Y. (2016). Musical exploration via streaming services: The Norwegian experience. Popular Communication, 14(3), 127-136. Retrieved from https://doi.org/10.1080/15405702.2016.1193183. doi:10.1080/15405702.2016.1193183

Lalonde, P.-É. (2014). Study Concerning Fair Compensation for Music Creators in the Digital Age. Retrieved 


\section{SPOTIFY PLAYLIST AUSTRALIA}

from Nashville: http://www.songwriters.ca/studyconcerningfaircompensation2014.aspx

Marshall, L. (2013). The Structural Functions of Stardom in the Recording Industry. Popular Music and Society, 36(5), 578-596. Retrieved from https://doi.org/10.1080/03007766.2012.718509. doi:10.1080/03007766.2012.718509

Marshall, L. (2015). 'Let's keep music special. F-Spotify': on-demand streaming and the controversy over artist royalties. Creative Industries Journal, 8(2), 177-189. Retrieved from http://dx.doi.org/10.1080/17510694.2015.1096618. doi:10.1080/17510694.2015.1096618

Meier, L. (2013). Promotional Ubiquitous Musics: New Identities and Emerging Markets in the Digitalizing Music Industry. (PhD Monograph), The University of Western Ontario, Electronic Thesis and Dissertation Repository. Retrieved from http://ir.lib.uwo.ca/etd/1096 (1096)

Meier, L. M. (2017). Popular Music as Promotion: Music and Branding in the Digital Age: John Wiley \& Sons. Morgan, B. (2019). Whose tool for what purpose? The struggle for cultural industry infrastructure in Liberia. In S. Labadi (Ed.), The Cultural Turn in International Aid: Impacts and Challenges for Heritage and the Creative Industries (pp. forthcoming): Routledge.

Morris, J. W. (2015). Curation by code: Infomediaries and the data mining of taste. European Journal of Cultural Studies, 18(4-5), 446-463. Retrieved from http://journals.sagepub.com/doi/abs/10.1177/1367549415577387. doi:10.1177/1367549415577387

Morris, J. W., \& Powers, D. (2015). Control, curation and musical experience in streaming music services. Creative Industries Journal, 8(2), 106-122. Retrieved from http://dx.doi.org/10.1080/17510694.2015.1090222. doi:10.1080/17510694.2015.1090222

Mulligan, M. (2018). Are Record Labels Facing an A\&R Crisis? Retrieved from https://musicindustryblog.wordpress.com/2018/07/30/are-record-labels-facing-an-ar-crisis/

Negus, K. (1999). Music Genres and Corporate Cultures. London: Routledge.

Negus, K. (2002). THE WORK OF CULTURAL INTERMEDIARIES AND THE ENDURING DISTANCE BETWEEN PRODUCTION AND CONSUMPTION. Cultural Studies, 16(4), 501-515. Retrieved from https://doi.org/10.1080/09502380210139089. doi:10.1080/09502380210139089

Nicolaou, A. (2017, 17 Jauary 2017). How streaming saved the music industry. Financial Times. Retrieved from https://www.ft.com/content/cd99b95e-d8ba-11e6-944b-e7eb37a6aa8e

Nordgård, D. (2018). The Music Business and Digital Impacts: Innovations and Disruptions in the Music 


\section{SPOTIFY PLAYLIST AUSTRALIA}

Industries: Springer.

Nowak, R. (2016). When is a discovery? The affective dimensions of discovery in music consumption. Popular Communication, 14(3), 137-145. Retrieved from http://dx.doi.org/10.1080/15405702.2016.1193182. doi:10.1080/15405702.2016.1193182

Pelly, L. (2017). The Secret Lives of Playlists. Retrieved from https://watt.cashmusic.org/writing/thesecretlivesofplaylists

Peoples, G. (2015). How 'Playola' Is Infiltrating Streaming Services: Pay for Play Is 'Definitely Happening'. Billboard. Retrieved from http://www.billboard.com/articles/business/6670475/playola-promotionstreaming-services

Pierce, D. (2017). The Secret Hit-Making Power of the Spotify Playlist. WIRED. Retrieved from https://www.wired.com/2017/05/secret-hit-making-power-spotify-playlist/

Powers, D. (2015). Intermediaries and intermediation. In A. Bennett \& S. Waksman (Eds.), The Sage Handbook of Popular Music. (pp. 120-134). Thousand Oaks, California: Sage Publications Ltd.

Prey, R. (2016). Musica Analytica: The Datafication of Listening. In R. Nowak \& A. Whelan (Eds.), Networked Music Cultures: Contemporary Approaches, Emerging Issues (pp. 31-48). London: Palgrave Macmillan UK.

Ray, M. B. (2017). Digital Connectivity and Music Culture: Artists and Accomplices. Cham: Springer International Publishing: Cham.

Rogers, I. (2013). The Hobbyist Majority and the Mainstream Fringe. In S. Baker, A. Bennett, \& J. Taylor (Eds.), Redefining mainstream popular music (pp. 162-173). London, UK: Routledge.

Seaver, N. (2018). Captivating algorithms: Recommender systems as traps. Journal of Material Culture, In press.

Shaw, L. (2018). Spotify's Playlists Are More Powerful Than Radio. Retrieved from https://www.bloomberg.com/news/articles/2018-03-23/spotify-s-playlists-are-more-powerful-than$\underline{\text { radio }}$

Sinnreich, A. (2016). Slicing the pie: the search for an equitable recorded music economy. In P. Wikström \& R. DeFillippi (Eds.), Business Innovation and Disruption in the Music Industry: Edward Elgar Publishing. Spotify. (2017). Fan Insights is Now 'Spotify for Artists' and Available to All Artists [Press release]. Retrieved from https://artists.spotify.com/blog/fan-insights-is-now-spotify-for-artists 


\section{SPOTIFY PLAYLIST AUSTRALIA}

Spotify. (2018a). Now in Beta: Upload your music in Spotify for Artists [Press release]. Retrieved from https://artists.spotify.com/blog/now-in-beta-upload-your-music-in-spotify-for-artists

Spotify. (2018b). Share New Music for Playlist Consideration [Press release]. Retrieved from https://artists.spotify.com/blog/share-new-music-for-playlist-consideration

Sterne, J. (2014). There Is No Music Industry. Media Industries Journal, 1(1), 50-55. Retrieved from http://www.mediaindustriesjournal.org/index.php/mij/article/view/17/26.

Strong, C., \& Rogers, I. (2016). She-Riffs: Gender and the Australian Experience of Alternative Rock and Riot Grrrl in the 1990s. Journal of World Popular Music, 3(1), 38-53.

Swift, T. (2015, 21 June 2015). To Apple, Love Taylor. Retrieved from http://taylorswift.tumblr.com/post/122071902085/to-apple-love-taylor

Ugwu, R. (2016). Inside the Playlist Factory. Retrieved from https://www.buzzfeed.com/reggieugwu/theunsung-heroes-of-the-music-streaming-boom

Vonderau, P. (2017). The Spotify Effect: Digital Distribution and Financial Growth. Television \& New Media, 1527476417741200. Retrieved from https://doi.org/10.1177/1527476417741200. doi:10.1177/1527476417741200

Webster, J., Gibbins, N., Halford, S., \& Hracs, B. J. (2016). Towards a theoretical approach for analysing music recommender systems as sociotechnical cultural intermediaries. Paper presented at the Proceedings of the 8th ACM Conference on Web Science, Hannover, Germany.

Wikström, P. (2013). The Music Industry : Music in the Cloud, 2nd Edition: Polity.

Williamson, J., \& Cloonan, M. (2007). Rethinking the music industry. Popular Music, 26(2), 305-322. doi:10.1017/S0261143007001262 